\title{
Pengaruh Motif Penggunaan Media Sosial Instagram terhadap Kepuasan Konsumen (Studi pada Followers @pluffyschoice)
}

\author{
Cassandra Willianti, Roswita Oktavianti \\ cassandra.915150165@stu.untar.ac.id,Roswitao@fikom.untar.ac.id
}

\begin{abstract}
Fakultas Ilmu Komunikasi Universitas Tarumanagara

In this era, social media is widely accessed by young people generation. The most used social media is Instagram. Instagram isn't just a place for sharing photos and videos, but also can be a place of business opportunities. This study is intended to determine impacts between the motives for using social media Instagram and customer satisfaction. The researcher used The Uses and Gratification Theory on social media and distributed questionnaires to 100 respondents who are followers of @Pluffyschoice and using kuantitaif method. To process the data, researcher used the SPSS program ver. 19. The result shows that the motive of social media Instagram uses has an effect on customer satisfaction. The effect is moderate and was ruled by $28 \%$. The researcher conclude that is the motive of using social media Instagram increases, customer satisfaction also will be increase.
\end{abstract}

Keywords: uses and gratification theory, motive to use, social media instagram

\begin{abstract}
Abstrak
Media sosial banyak diakses oleh generasi muda. Media sosial yang paling sering digunakan adalah Instagram. Instagram bukan hanya sarana berbagi foto dan video, tetapi juga dapat menjadi peluang berbisnis. Penelitian ini ingin mengetahui apakah ada pengaruh antara motif penggunaan media sosial Instagram terhadap kepuasan konsumen. Peneliti memakai teori uses and gratification di media sosial. Peneliti menyebarkan kuesioner kepada 100 responden yang merupakan pengikut akun online shop Instagram @ Pluffyschoice dan menggunakan metode kuantitatif. Dalam mengolah data, peneliti menggunakan program SPSS ver.19. Hasilnya terdapat pengaruh motif penggunaan media sosial Instagram terhadap kepuasan konsumen bersifat sedang dan sebesar $28 \%$. Apabila motif penggunaan media sosial Instagram meningkat maka kepuasan konsumen juga akan meningkat.
\end{abstract}

Kata kunci: motif penggunaan, kepuasan konsumen, media sosial Instagram.

\section{Pendahuluan}

Media sosial banyak dipakai oleh masyarakat untuk berbicara dan dapat informasi karena semakin canggih media sosial memberi informasi terkini, mudah dijangkau oleh orang banyak hanya dengan memakai smartphone dan media yang murah (Miranda, 2017).

Pada tanggal 30 Januari 2018, dari total populasi Indonesia sebanyak 265,4 juta jiwa, pengguna aktif media sosialnya mencapai 130 juta (https://tekno.kompas.com). Banyaknya pengguna aktif menunjukkan bahwa orang Indonesia gemar menggunakan media sosial. Teori Uses and Gratification menunjukkan sisi audiens sebagai pihak paling aktif memilih pilihan media yang digunakan. Pada Teori Uses and Gratification dikatakan audiens aktif untuk memilih media yang digunakan agar memenuhi kebutuhannya (Nurudin, 2007). 
Terdapat lima asumsi Teori Uses and Gratification, yaitu pengguna aktif dan memakai media untuk mencapai tujuan, keinginan mencapai kepuasan pilihan media tertentu, media berkompetisi bersama sumber lain untuk kepuasan, orang memiliki kesadaran diri akan penggunaan media, minat dan motif, dan penilaian mengenai media hanya dapat dinilai oleh khalayak (West dan Turner, 2014).

Motif adalah dorongan seseorang yang membuat ingin melakukan sesuatu. Empat motif yang mendorong seorang menggunakan media adalah motif informasi, motif identitas pribadi, motif integrasi dan identitas sosial, dan motif hiburan (Ardianto, 2005). Sementara itu, kepuasan konsumen sendiri diartikan sebagai tingkat perasaan konsumen setelah membandingkan apa yang diterima dan harapannya (Umar, 2005). Dalam kepuasan konsumen terdapat tiga indikator, yaitu kesesuaian harapan, minat menggunakan kembali, dan kesediaan merekomendasikan (Tjiptono, 2015).

Instagram bukan hanya tempat membagi foto dan video, tetapi juga dapat menjadi peluang berbisnis. Banyaknya pengguna Instagram membuat pebisnis menggunakan media sosial tersebut sebagai tempat berkomunikasi dengan pembelinya. Kesempatan ini digunakan oleh akun Instagram @Pluffyschoice dalam berkomunikasi dengan konsumen atau audiensnya.

Penulis memilih variabel indepeden yaitu penggunaan media pada media sosial Instagram dan variabel dependen yaitu kepuasan konsumen. Rumusan masalah dalam penelitian ini adalah apakah terdapat pengaruh motif penggunaan media sosial Instagram terhadap kepuasan konsumen.

\section{Metode Penelitian}

Penulis menggunakan metode penelitian kuantitatif dengan pendekatan survei. Metode survei adalah penelitian yang dilakukan memakai angket pada populasi baik besar maupun kecil (Sugiyono, 2013).

Penelitian ini ingin mengetahui apakah dimensi variabel independen (variabel $\mathrm{X}$ ) memiliki pengaruh dengan variabel dependen (variabel $\mathrm{Y}$ ).

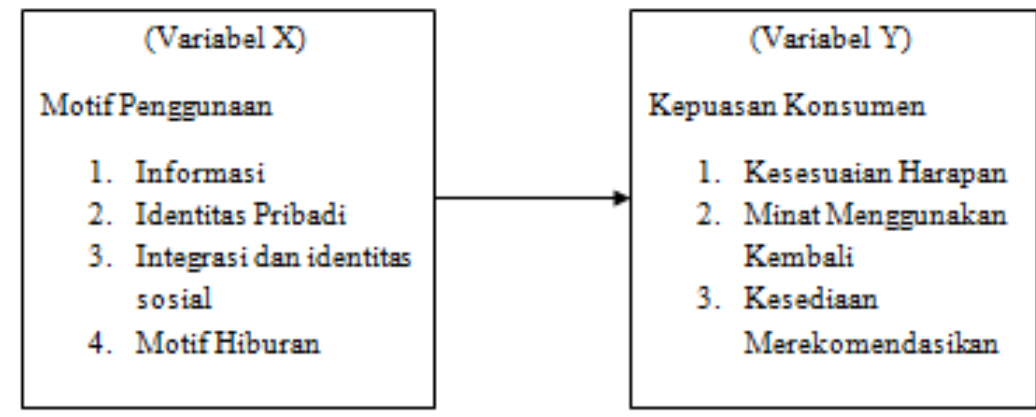

Gambar 1. Kerangka Pemikiran

Populasi penelitian ini adalah konsumen yang mengikuti (follow) akun @Pluffyschoice lewat Instagram. Jumlah followers pada akun Instagram @Pluffyschoice adalah 231k atau 231.000 followers. Populasi besar tidak mungkin diteliti semua, maka penulis dapat memakai sampel yang diambil dari populasi (Sugiyono, 2011).

Peneliti menggunakan 100 responden dengan syarat sampel adalah mengikuti (follow) dan pernah membeli produk lewat Instagram @Pluffyschoice. Teknik pemilihan sampel yang dipakai adalah nonprobability sampling. Berarti bahwa 
populasi memiliki kesempatan yang sama untuk dipilih sebagai sampel. Nonprobability sampling adalah teknik mengambil sampel yang tidak memberi peluang sama di setiap populasi untuk dipilih menjadi sampel (Sugiyono, 2011).

Variabel beserta indikator yang peneliti gunakan dalam variabel X (Motif Penggunaan) sebagai berikut:

1. Motif informasi: dimana dapat ingin tahu akan keadaan atau peristiwa di sekitar.

2. Motif identitas pribadi: ingin menemui nilai yang berhubungan dengan diri sendiri.

3. Motif integrasi dan identitas sosial: mendapat nilai yang berhubungan dengan empati sosial.

4. Motif hiburan: dapat melepaskan diri dari permasalahan, digunakan untuk mengisi waktu luang, penyaluran emosi, bersantai dan untuk menyelesaikan masalah.

Lalu variabel Y (Kepuasan Konsumen) sebagai berikut:

1. Kesesuaian harapan: tingkat kesesuaian antara kinerja produk yang dirasakan oleh pelanggan atau dengan yang dirasakan oleh pelanggan.

2. Minat menggunakan kembali: bersedia untuk menggunakan kembali produk karena mendapat manfaat dan nilai-nilai tertentu.

3. Kesediaan merekomendasikan: kesediaan konsumen untuk merekomendasikan produk yang dirasakan kepada orang lain (Tjiptono, 2015:101).

Dalam pengumpulan data penulis memilih teknis dengan menyebar angket atau kuisioner. Penulis menyebarkan 100 kuisioner kepada 100 responden secara online menggunakan google form. Dalam hal ini, data primer penelitian ini menggunakan cara kuisioner kepada narasumber atau responden, sedangkan data sekunder penelitian ini dengan membaca buku, jurnal, maupun penelitian lainnya serta artikel internet sebagai referensi penulisan.

\section{Hasil Penelitian}

Data yang diperoleh diolah dengan memakai program IBM SPSS Statistic for Windows ver 19. didapat hasil dengan $\mathrm{R}_{\text {hitung }}$ di bawah, sedangkan untuk Rtabel dengan besar signifikan $\alpha=0,05$ dan $\mathrm{N}=100$ adalah 0,2 . Hasil uji validitas Variabel $\mathrm{X}$ sebagai berikut:

Tabel 1. Hasil Uji Validitas Variabel X (Motif Penggunaan)

\begin{tabular}{|c|c|c|c|}
\hline $\mathbf{X}$ & $\begin{array}{c}\text { Corrected Item - Total } \\
\text { Correlation }\end{array}$ & Nilai Patokan & Keterangan \\
\hline P1 & 0.568 & 0,2 & Valid \\
\hline P2 & 0.531 & 0,2 & Valid \\
\hline P3 & 0.552 & 0,2 & Valid \\
\hline P4 & 0.588 & 0,2 & Valid \\
\hline P5 & 0.633 & 0,2 & Valid \\
\hline P6 & 0.597 & 0,2 & Valid \\
\hline P7 & 0.692 & 0,2 & Valid \\
\hline P8 & 0.428 & 0,2 & Valid \\
\hline P9 & 0.664 & 0,2 & Valid \\
\hline P10 & 0.662 & 0,2 & Valid \\
\hline
\end{tabular}

Sumber: Pengolahan Data SPSS ver. 19 
Validitas berarti mengukur valid dan tidaknya pernyataan. Untuk menyatakan bahwa pertanyaan valid atau tidak, ditunjukkan angka korelasi di atas 0,2 maka valid (Nisfiannoor, 2009:298). Hasil pada tabel Motif Penggunaan menunjukkan 10 butir pertanyaan dinyatakan sebagai pertanyaan yang valid.

Tabel 2. Uji Validitas Variabel Y (Kepuasan Konsumen)

\begin{tabular}{|c|c|c|c|}
\hline $\mathbf{Y}$ & $\begin{array}{c}\text { Corrected Item - } \\
\text { Total Correlation }\end{array}$ & Nilai Patokan & Keterangan \\
\hline P11 & 0.603 & 0,2 & Valid \\
\hline P12 & 0.591 & 0,2 & Valid \\
\hline P13 & 0.416 & 0,2 & Valid \\
\hline P14 & 0.599 & 0,2 & Valid \\
\hline P15 & 0.398 & 0,2 & Valid \\
\hline P16 & 0.470 & 0,2 & Valid \\
\hline P17 & 0.414 & 0,2 & \\
\hline
\end{tabular}

Sumber: Pengolahan Data SPSS ver. 19

Hasil Kepuasan Konsumen menunjukkan 7 butir pertanyaan dinyatakan sebagai pertanyaan yang valid.

Tabel 3. Hasil Uji Realibilitas

Reliability Statistics

\begin{tabular}{|r|r|}
\hline Cronbach's Alpha & N of Items \\
\hline .742 & 18 \\
\hline
\end{tabular}

Sumber: Pengolahan Data SPSS ver. 19

Syarat minimum untuk dinyatakan reliabel adalah apabila hasil korelasinya 0,7 atau lebih maka item tersebut memberikan tingkat reliabel yang cukup tinggi, tetapi apabila nilai korelasinya di bawah 0,7 maka item tersebut dinyatakan tidak reliabel (Sugiyono, 2017). Hasil dari uji reliabilitas menunjukkan bahwa seluruh pertanyaan variabel $\mathrm{X}$ dan $\mathrm{Y}$ memiliki nilai 0,742 dengan artian variabel $\mathrm{X}$ dan $\mathrm{Y}$ memiliki instrumen yang reliabel. 
Cassandra Willianti, Roswita Oktavianti: Pengaruh Motif Penggunaan Media Sosial Instagram terhadap Kepuasan Konsumen (Studi pada Followers @ pluffyschoice)

Tabel 4. Hasil Uji Normalitas

Sumber: Pengolahan Data SPSS ver. 19

One-Sample Kolmogorov-Smirnov Test

\begin{tabular}{|c|c|c|}
\hline & & $\begin{array}{l}\text { Unstandardi } \\
\text { zed Residual }\end{array}$ \\
\hline \multicolumn{2}{|l|}{$\mathrm{N}$} & 100 \\
\hline \multirow[t]{2}{*}{ Normal Parameters $\mathrm{ab}^{\mathrm{b}}$} & Mean & .0000000 \\
\hline & Std. Deviation & 3.00226683 \\
\hline Most Extreme & Absolute & .130 \\
\hline \multirow[t]{2}{*}{ Differences } & Positive & .058 \\
\hline & Negative & -.130 \\
\hline \multicolumn{2}{|l|}{ Kolmogorov-Smirnov Z } & 1.299 \\
\hline \multicolumn{2}{|l|}{ Asymp. Sig. (2-tailed) } & .068 \\
\hline
\end{tabular}

Bila dilihat di atas, hasil uji menunjukkan 0,068 dimana hasil lebih besar dari 0,05. Maka dapat dikatakan data berdistribusi normal.

Tabel 5. Hasil Uji Koefisien Korelasi

Model Summary ${ }^{b}$

\begin{tabular}{|l|c|r|r|r|}
\hline Model & $\mathrm{R}$ & $\mathrm{R}$ Square & $\begin{array}{c}\text { Adjusted R } \\
\text { Square }\end{array}$ & $\begin{array}{r}\text { Std. Error of } \\
\text { the Estimate }\end{array}$ \\
\hline 1 & $.529^{\mathrm{2}}$ & .280 & .272 & 3.01755 \\
\hline
\end{tabular}

a. Predictors: (Constant), motif penggunaan

b. Dependent Variable: kepuasan

Sumber: Pengolahan Data SPSS ver. 19

Tabel 5 menunjukkan Motif Penggunaan terhadap Kepuasan Konsumen sebesar 0,529, karena hasil berada di antara 0,40 - 0,599 maka kesimpulannya motif penggunaan terhadap kepuasan konsumen ada hubungan dan sifat hubungan adalah sedang. Hubungan yang dimiliki adalah positif sehingga jika motif penggunaan meningkat maka kepuasan konsumen juga akan meningkat.

Tabel 6. Hasil Uji Koefisien Determinasi

\begin{tabular}{|l|c|r|c|c|}
\hline Model & $R$ & R Square & $\begin{array}{c}\text { Adjusted R } \\
\text { Square }\end{array}$ & $\begin{array}{c}\text { Std. Error of the } \\
\text { Estimate }\end{array}$ \\
\hline 1 & $.529^{\circ}$ & .280 & .272 & 3.01755 \\
\hline
\end{tabular}
a. Predictors: (Constant), moff penggunaan
b. Dependent Variable: kepuasan

Sumber: Pengolahan Data SPSS ver. 19 
Tabel 6 menunjukkan hasil $\mathrm{R}^{2}$ adalah 0,280. Kepuasan konsumen dipengaruhi sebesar $28 \%$ oleh motif penggunaan, sementara sisanya $72 \%$ dipengaruhi oleh hal lain.

Tabel 7. Hasil Analisis Regresi Linear Sederhana

(Sumber: Pengolahan Data SPSS ver. 19)

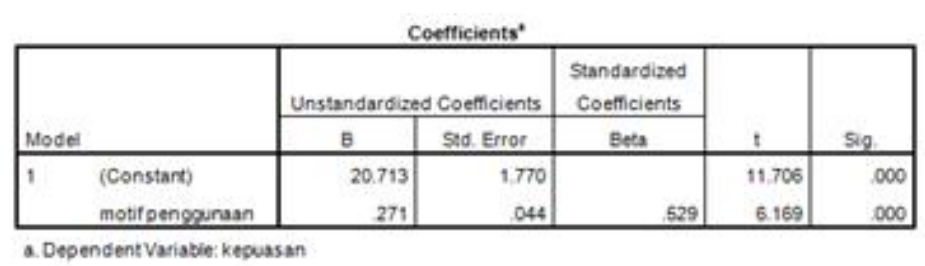

Sumber: Pengolahan Data SPSS ver. 19

Tabel 7 menunjukkan, nilai 20,731 menyatakan bila tidak ada kenaikan variabel X (motif penggunaan), maka variabel Y (kepuasan konsumen) mencapai 20,731. Setiap ada penambahan 1 angka atau perubahan variabel $X$ (motif penggunaan), maka variabel Y (kepuasan konsumen) akan mengalami kenaikan sebesar 0,271.

Data menunjukkan nilai $t_{\text {tabel }}$ variabel $\mathrm{X}$ adalah 1,987 dan nilai $t_{\text {hitung }}$ variabel $X$ yaitu 6,169 , maka $t_{\text {hitung }} \geq t_{\text {tabel }}$ yaitu $6,169 \geq 1,987$, serta nilai sig $<\alpha$ yaitu 0,000 $<0,05$. Hasilnya ialah Ho ditolak dan Ha diterima, artinya terdapat pengaruh motif penggunaan media sosial instagram @ pluffyschoice terhadap kepuasan konsumen. Motif penggunaan berpengaruh signifikan terhadap kepuasan konsumen artinya hasil penelitian tidak hanya berlaku pada sampel tetapi hasil berlaku juga di populasi.

\section{Simpulan}

Hasil penelitian ini menunjukan terdapat hubungan motif penggunaan media sosial Instagram terhadap kepuasan konsumen dan sifat hubungan tersebut adalah sedang. Hubungan yang dimiliki adalah positif sehingga jika motif penggunaan meningkat maka kepuasan konsumen juga akan meningkat. Setelah dilakukan survei terhadap responden didapatkan bahwa motif penggunaan media mempengaruhi kepuasan konsumen @ Pluffyschoice sebesar 28\% dan 72\% adalah faktor lainnya.

Variabel X (Motif Penggunaan) memiliki indikator yang paling berpengaruh yaitu Motif Informasi, sedangkan Variabel Y (Kepuasan Konsumen) yaitu Kesediaan Merekomendasikan. Pengaruh termasuk signifikan, sehingga hasil ini tidak hanya mempengaruhi sampel yang diambil yaitu 100 orang, tetapi juga mempengaruhi populasi penelitian (follower Instagram @Pluffyscoice).

\section{Ucapan Terima Kasih}

Penulis berterima kasih kepada Ibu Roswita Oktavianti, S.Sos., M.Si., yang selalu meluangkan waktu untuk memberikan petunjuk dan arahan selama penulisan penelitian ini sehingga dapat selesai tepat waktu. Kepada orang tua, kakak, dan Diandra Awvina atas waktu dan bantuannya. 
Cassandra Willianti, Roswita Oktavianti: Pengaruh Motif Penggunaan Media Sosial Instagram terhadap Kepuasan Konsumen (Studi pada Followers @pluffyschoice)

\section{Daftar Pustaka}

Ardianto, Karlinah \& Komala. (2005). Komunikasi Massa Suatu Pengantar, Cetakan Kedua. Bandung: Simbiosa.

https://tekno.kompas.com/read/2018/03/01/10340027/riset-ungkap-pola-pemakaianmedsos-orang-indonesia. diakses pada tanggal 27 Februari 2019 pukul 00.34 WIB.

McQuail, Denis. (1991). Teori Komunikasi Massa. Jakarta: Erlangga.

Miranda, Sofia. 2017. Pengaruh Instagram Sebagai Media Online Shopping Fashion Terhadap Perilaku Konsumtif Mahasiswa Fakultas Ilmu Sosial dan Ilmu Politik Universitas Riau. Jurnal Online Mahasiswa Fakultas Ilmu Sosial dan Ilmu Politik, 4 (1), 1-15.

Nisfiannoor, Muhammad. (2009). Pendekatan Statistika Modern Untuk Ilmu Sosial. Jakarta: Salemba Empat.

Nurudin. (2007). Pengantar komunikasi massa. Jakarta: PT Raja Grafindo Persada.

Sugiyono. (2011). Metode Penelitian Kuantitatif, Kualitatif dan R\&D. Bandung: Alfabeta.

Sugiyono. (2013). Metode Penelitian Kuantitatif, Kualitatif dan R\&D. Bandung: Alfabeta.

Tjiptono, Fandy. (2015). Strategi Pemasaran, Edisi 4. Yogyakarta: Andi.

Umar, Husein. (2005). Riset Pemasaran dan Perilaku Konsumen. Jakarta: PT Gramedia Pusat.

West, Richard dan Lynn H. Turner. (2014). Pengantar Teori Komunikasi: Analisis dan Aplikasi, Edisi 3, Buku 2. Jakarta: Salemba Humanika. 